\title{
Skeletal Muscle Insulin Resistance in Endocrine Disease
}

\author{
Melpomeni Peppa, ${ }^{1}$ Chrysi Koliaki, ${ }^{1}$ Panagiotis Nikolopoulos, ${ }^{1}$ and Sotirios A. Raptis ${ }^{1,2}$ \\ ${ }^{1}$ Endocrine Unit, Second Department of Internal Medicine-Propaedeutic, Research Institute and Diabetes Center, \\ Athens University Medical School, Attikon University Hospital, 1 Rimini Street, Haidari, 12 462, Athens, Greece \\ ${ }^{2}$ Hellenic National Center for the Research, Prevention and Treatment of Diabetes and Its Complications (H.N.D.C), \\ 3 Ploutarchou Street, 10675 Athens, Greece
}

Correspondence should be addressed to Melpomeni Peppa, molypepa@otenet.gr

Received 10 November 2009; Accepted 3 February 2010

Academic Editor: Guy M. Benian

Copyright ( $) 2010$ Melpomeni Peppa et al. This is an open access article distributed under the Creative Commons Attribution License, which permits unrestricted use, distribution, and reproduction in any medium, provided the original work is properly cited.

\begin{abstract}
We summarize the existing literature data concerning the involvement of skeletal muscle (SM) in whole body glucose homeostasis and the contribution of SM insulin resistance (IR) to the metabolic derangements observed in several endocrine disorders, including polycystic ovary syndrome (PCOS), adrenal disorders and thyroid function abnormalities. IR in PCOS is associated with a unique postbinding defect in insulin receptor signaling in general and in SM in particular, due to a complex interaction between genetic and environmental factors. Adrenal hormone excess is also associated with disrupted insulin action in peripheral tissues, such as SM. Furthermore, both hyper- and hypothyroidism are thought to be insulin resistant states, due to insulin receptor and postreceptor defects. Further studies are definitely needed in order to unravel the underlying pathogenetic mechanisms. In summary, the principal mechanisms involved in muscle IR in the endocrine diseases reviewed herein include abnormal phosphorylation of insulin signaling proteins, altered muscle fiber composition, reduced transcapillary insulin delivery, decreased glycogen synthesis, and impaired mitochondrial oxidative metabolism.
\end{abstract}

\section{Introduction}

Insulin resistance (IR) constitutes a common and broadly prevalent metabolic disorder, which seems to govern the pathophysiology of diabetes mellitus, metabolic syndrome, and obesity [1]. Furthermore, IR appears to be a clinically important manifestation of various endocrine diseases, including polycystic ovary syndrome (PCOS), thyroid and adrenal diseases, as well as their complications [2-5]. From a pathophysiological point of view, IR appears to be the end result of a complex interaction between genetic predisposition and environmental factors.

In general, IR indicates the presence of an impaired peripheral tissue response to endogenously secreted insulin. It is typically manifested as both decreased insulin-mediated glucose uptake (IMGU) at the level of adipose and skeletal muscle (SM) tissue, and as an impaired suppression of hepatic glucose output. A significant body of evidence supports the critical role of SM for the development of IR, most commonly through an interactive cross-talk with adipose and liver tissue [6-8].

\section{Skeletal Muscle and Glucose Homeostasis}

SM plays a crucial role in maintaining systemic glucose metabolism, accounting for $85 \%$ of whole body insulinstimulated glucose uptake [7]. In SM, insulin stimulates glucose uptake by increasing the translocation of glucose transport molecules, mainly GLUT4, from intracellular vesicles to the cell surface [9]. This process is initiated upon binding of insulin to the transmembrane receptor and is mediated through an intracellular molecular signaling cascade, including the consecutive phosphorylation of several cytosolic proteins, such as insulin receptor substrate molecules (IRS), phosphatidylinositol 3-kinase (PI3K), and protein kinase B (PKB/Akt) [9]. To date, among the four different IRS molecules that have been cloned, IRS-1 and IRS-2 appear to be the predominant isoforms expressed in SM. IRS molecules serve as docking sites for specific signaling proteins, such as PI3K, and play a key role for downstream insulin signaling [9]. Recent studies have proposed four different PI3K isoforms in human SM, involved in the insulindependent PI3K signaling pathways [9]. These isoforms 
elicit different, rather specific, insulin-induced responses. Although the exact molecular link between PI3K and glucose transport has not been fully elucidated yet, protein kinase B $(\mathrm{PKB})$ or Akt $(\mathrm{Akt} / \mathrm{PKB})$ and members of the protein kinase $\mathrm{C}$ (PKC) family have been suggested as important molecules in the metabolic pathway of insulin-signaling, leading ultimately to increased intracellular glucose transport [9].

The activated insulin-signaling cascade results in the release of GLUT4 from an intracellular reservoir compartment and its translocation and final fusion with the plasma membrane. This is the rate-limiting step for the uptake of glucose, which is transported across the plasma membrane and further processed by either oxidative (glycolysis) or nonoxidative pathways (glycogen synthesis) [9].

However, glucose disposal in SM is not entirely independent from the metabolic effects of insulin on other peripheral tissues, such as adipose tissue (AT). It seems that IR at the level of SM might be also secondarily induced to adipose tissue IR. More specifically, it has been shown that mice with AT-specific knockout of GLUT4 had an impaired IMGU in SM as well, despite preserved GLUT4 expression in this tissue [6]. Moreover, AT overexpression of GLUT4 reversed the impaired IMGU observed in SM-specific GLUT4 knockout mice, without concomitantly restoring glucose transport in SM [8]. These experimental findings have highlighted the importance of interactive communication (cross-talk) between AT and SM in terms of regulating glucometabolic balance.

\section{Skeletal Muscle and Insulin Resistance}

$\mathrm{SM}$ is a principal tissue responsible for IMGU which has recently gained a lot of interest, as a major site involved in peripheral IR. Most of the available data have derived from studies in type 2 diabetes mellitus (T2DM), where SM has emerged as an important insulin-resistant peripheral tissue, via molecular mechanisms that are currently being extensively investigated.

In vitro and in vivo data from humans and laboratory animals support a selective insulin-signaling defect at the level of glucose transport in SM. In type 2 diabetic patients, IMGU in SM has been found to be significantly reduced by about $50 \%$, without clarifying whether this is a permanent defect or rather a short-term downregulation secondary to the diabetic state. Furthermore, an additional possible explanation for the development of IR in SM is related to specific alterations in the insulin-signal transduction pathway, including decreased IRS-1 protein content, impaired IRS-1 phosphorylation, reduced PI3K activity, or altered protein expression of the regulatory subunit of PI3K $[9,10]$. Alterations in the expression or translocation of GLUT4 to the plasma membrane have been also implicated as potential pathogenetic mechanisms. However, whether these defects are actually a primary cause of IR or rather a secondary effect to an altered metabolic milieu remains still unresolved [11].

Despite the considerable body of evidence supporting the critical role of SM for the development of IR in many clinical entities, the exact underlying mechanisms have not been fully delineated and most commonly represent a complex interaction between multiple extrinsic and intrinsic factors.

3.1. The Role of Adipokines in Skeletal Muscle IR. Most commonly, IR in SM is considered to be the end result of a complex interaction involving several different tissues. AT can induce IR at the level of SM via secretion of adipokines, inflammatory mediators, and growth factors. Tumor necrosis factor $\alpha$ (TNF- $\alpha$ ), adiponectin, and leptin are the main adipokines that appear to be implicated in the development of cross-communication between AT and SM.

TNF- $\alpha$ is the main autocrine/paracrine AT-derived factor, triggering the release of free fatty acids (FFAs) from AT into bloodstream circulation. This is mainly dependent on nuclear factor $\kappa \mathrm{B}(\mathrm{NF} \kappa \mathrm{B})$ activation and is mediated by the suppression of many genes responsible for glucose and FFA uptake and utilization $[12,13]$. TNF- $\alpha$-mediated FFA release impairs insulin-signaling in insulin responsive peripheral tissues such as SM [10]. According to the lipid supply hypothesis, the increased FFA availability provides the predominant substrate for intermediate metabolism, resulting in increased $\mathrm{NADH} / \mathrm{NAD}^{+}$and acetyl-CoA/CoA ratios. Elevated FFA concentrations promote beta-oxidation, which diminishes glucose uptake and oxidation. In parallel, FFA clearance is decreased and their storage as triglyceride droplets in SM is significantly enhanced [14].

In addition, adiponectin, a protective adipokine secreted by adipocytes, plays a pivotal role for SM insulin sensitivity. Adiponectin stimulates FFA catabolism, either directly or indirectly through stimulation of PPAR- $\gamma$ nuclear receptors, and promotes a marked decrease of circulating FFA and glucose levels [15]. Last but not least, leptin, a hormone secreted predominantly by AT, acts both on hypothalamus and on target tissues including SM and is significantly involved in the regulatory mechanisms determining peripheral insulin action and sensitivity [16].

3.2. Defects in Skeletal Muscle Glycogen Synthesis. The primary site of postabsorptive glucose disposal is SM and the primary mechanism of glucose storage is through its conversion to glycogen. In states of IR, a deficiency in the nonoxidative glucose disposal has been primarily related to a defect in glycogen synthesis. Freymond et al. studied biopsies of vastus lateralis muscle, both before and during a hyperinsulinemic-euglycemic clamp, and demonstrated that human subjects with IR display decreased insulin-stimulated glycogen synthase activity [17]. This defect at the level of glycogen synthase activity and thus glycogen synthesis in $\mathrm{SM}$, provides a further pathogenetic mechanism, underlying systemic and muscle IR.

3.3. Glucocorticoids and Muscle IR. Chronic glucocorticoid excess, a typical biochemical feature of Cushing's syndrome, has been traditionally associated with IR in general. However, recent experimental observations suggest that glucocorticoids, as well as glucocorticoid receptor (GR) activity, can have adverse effects on peripheral insulin sensitivity. Reynolds et al., found increased GR mRNA levels and increased expression of glucocorticoid receptors in SM of 
men with IR and hypertension, implicating the dysregulation of glucocorticoid receptor expression and/or function as a possible underlying pathogenetic mechanism for IR in SM [18].

3.4. Skeletal Muscle Vascular Bed, Blood Flow, and Insulin Action. Insulin-mediated increased blood flow seems to be an important step for insulin delivery and glucose metabolism in peripheral tissues, including SM [19]. This theory was first introduced by Baron, et al. who showed a remarkable correlation between insulin-mediated whole body glucose uptake and leg blood flow over a broad spectrum of insulin sensitivities in normal and IR states [20]. These correlations were typically observed several hours after the initiation of an insulin clamp, namely, under steady state conditions [21, 22]. In addition, metacholine infusion increased leg blood flow and glucose uptake, while these were diminished after L-N-monomethyl arginine infusion [23]. The above observations support the important role of insulin-mediated blood flow for glucose uptake and insulin action.

Insulin regulates blood flow in peripheral tissues through a variety of mechanisms. Insulin induces dilatation of terminal arterioles and provides a constant rate of vasodilatation or vasoconstriction, in order to maximally extend the period of peripheral tissue perfusion. In this way, insulin enhances nutrient delivery and expands the surface area available for exchange of insulin, glucose, and other nutrients in peripheral tissues, including SM. Furthermore, after its binding to the receptor, insulin seems to promote its own translocation across the endothelial cell barrier [24]. Most of the research work in this field has been conducted on skin microvasculature [25], without, however, ensuring that the insulin-mediated vascular responses observed in skin reflect also those in SM. Although far more data need to be obtained, it is currently proposed that various factors impair the insulin-mediated vascular response and tissue delivery of nutrients such as glucose and insulin, mediating the process of IR in SM.

\section{Muscle Insulin Resistance and Endocrine Disease}

Although generalized and muscle IR remains a hot topic for the investigation of metabolic disease, it would be quite interesting to expand this research to a number of common and clinically relevant endocrine diseases, including PCOS, adrenal dysfunction, and thyroid disorders.

4.1. PCOS and Muscle IR. PCOS is a common endocrine disorder with a worldwide prevalence of $6 \%-7 \%$ among premenopausal women [26]. However, despite its steadily increasing prevalence, the fundamental underlying defect remains still speculative and seems to be multifactorial in origin. Beyond the reproductive abnormalities (chronic anovulatory dysfunction, infertility), women with PCOS display several metabolic abnormalities as well, including disorders of glucose metabolism and insulin action, which underlie the increased risk of developing impaired glucose tolerance and type 2 diabetes [27].

Women with PCOS exhibit basal hyperinsulinemia, decreased glucose-stimulated insulin release and IMGU, due to reduced hepatic insulin clearance and pancreatic $\beta$-cell dysfunction. In addition, they exhibit a generalized IR, which mainly involves an impaired insulin responsiveness of adipose tissue and SM $[2,28]$.

IR in PCOS is associated with a unique postbinding defect in insulin receptor signaling due to a complex interaction between intrinsic (genetically determined) and environmental factors [29]. It is supported that the disrupted insulin receptor tyrosine kinase activity in adipocytes and IRS-1associated PI3K activity in SM are the key elements in the IR pathogenetic process [30]. In addition, extrinsic factors including inflammatory mediators, adipokines, androgens, free fatty acids (FFAs), amino acids, and increased glucose levels have been all implicated in the pathogenesis of IR in PCOS.

4.1.1. Adipokines, Inflammatory Mediators, FFAs, and Muscle $I R$ in PCOS. In vitro studies have shown that cultured SM cells from women with PCOS display normal insulin sensitivity, while SM cells from in vivo studies in PCOS exhibit resistance to insulin, suggesting the important role of extrinsic factors in producing muscle IR in PCOS [28]. Among them, adipokines, TNF- $\alpha$, FFAs, amino acids, androgens, and increased glucose levels have been all postulated to be involved in the pathogenesis of IR in PCOS [31]. Increased TNF- $\alpha$ levels and elevated plasma interleukin-6 (IL-6) concentrations have been consistently reported in both obese and normal weight women with PCOS, indicating the significant contribution of chronic low-grade inflammation to IR $[32,33]$. As far as leptin is concerned, Pehlivanov and Mitkov reported higher serum leptin in PCOS demonstrating a positive correlation with IR, independently of markers of adiposity [34]. Data regarding adiponectin and resistin levels are rather conflicting in women with PCOS. These adipokines have been found either increased or conversely decreased, depending on the obesity status of the studied population $[35,36]$.

The existing data indicate that adipose tissue, which is also an insulin resistant site in PCOS, and especially when it is centrally accumulated, secretes increased levels of adipokines, FFA, and inflammatory mediators (TNF- $\alpha$, IL-6), which in turn promote IR at the level of SM via a vicious cycle. In particular, elevated FFA levels have been consistently suggested in PCOS, especially when increased visceral fat is also present. This was well described by Ek et al. who reported an increased rate of visceral fat lipolysis in PCOS, suggesting a genetically determined upregulation in visceral fat lipolysis, associated with a selective increase in the function of both protein kinase A (PKA) and hormonesensitive lipase (HSL) [37]. It is obvious that the increased FFA influx has detrimental effects for insulin metabolic signaling in SM $[28,37]$.

4.1.2. Androgens and Muscle IR. Multiple studies suggest the association between androgen excess and IR in women with 
PCOS, but their cross-sectional nature does not allow safe conclusions about causality [31].

On one hand, hyperandrogenemia in women with PCOS appears to be an effect of the augmented steroidogenesis by hyperinsulinemia secondary to IR $[38,39]$. On the other hand, hyperandrogenemia induces generalized and muscle IR, through either a direct effect of androgens on insulin action in AT and SM, or indirectly by affecting lipid metabolism and body fat distribution [31]. Hyperandrogenemia-induced IR is selective, affecting mainly the metabolic but not the mitogenic actions of insulin, since insulin-stimulated ovarian steroidogenesis is perfectly maintained [40]. Androgen excess has been associated with some of the typical insulin-signaling defects in PCOS [41]. Most of these effects have been mostly studied in female rats, while there is a relative paucity of similar clinical studies. Testosterone administration to female adult rats for 8-12 weeks caused hyperinsulinemia in both intact and ovariectomized animals [42], while in the latter it induced a $50 \%$ reduction in IMGU into SM. Impaired SM insulin action was combined with fewer type 1 muscle fibers (slow twitch, oxidative) and increased type 2 fibers (fast twitch, insulin resistant). In the same study, a decreased SM capillary density and an impaired muscle glycogen synthase activity were also reported, contributing to the observed IR of SM [43]. It seems that postinsulin receptor signaling events are involved in testosterone-induced IR in SM in this rat model. In support of this, experimental data in primary differentiated rat myotubes have demonstrated a synergistic interaction between testosterone and insulin in phosphorylation of intracellular signaling proteins (phosphorylation of IRS-1 at serine residues), resulting in a dissociation of insulin receptor from the PI3K signaling cascade and an impaired insulin metabolic signaling [44].

Summarizing the existing data, androgens promote IR at the tissue level of SM by reducing capillary network formation for adequate delivery of insulin to SM, switching muscle fiber isoforms, reducing glycogen synthase activity and impairing insulin-mediated GLUT4 plasma membrane translocation [44].

However, the finding of hyperinsulinemia in PCOS patients raises the questions what the cause is and what the effect is. Most of the existing clinical data suggest, without providing definitive confirmation, that hyperinsulinemia causes hyperandrogenism, more than the other way around [45].

\subsubsection{Molecular Defects and Muscle IR in PCOS}

(a) In Vitro and In Vivo Studies. Current evidence suggests that excessive serine phosphorylation of the insulin receptor or downstream signaling molecules plays a pivotal role for the pathogenesis of muscle IR in PCOS [46]. In vitro studies in cultured SM cells from obese and nonobese patients with PCOS reported an abnormal phosphorylation pattern, consisting in decreased tyrosine autophosphorylation of the insulin receptor and increased serine phosphorylation, similarly to the phosphorylation abnormalities observed in PCOS cultured skin fibroblasts [46].
Corbould et al. who studied cultured SM cells of obese nondiabetic women with PCOS and of age- and BMI-matched control women, did not observe a decrease in IMGU and basal autophosphorylation in vitro, while insulin-stimulated tyrosine phosphorylation of the insulin receptor was found to be normal [29]. Moreover, the protein expression of insulin receptor $\beta$-subunit, IRS-2, PI3K, and GLUT4 was similar to that of controls. However, a number of molecular signaling abnormalities were documented including a 35\% increased expression and a two-fold increased constitutive phosphorylation of IRS- 1 at serine 312, decreased IRS-1-associated PI3K activity after adjusting for the increased expression of IRS-1, decreased baseline IRS-2-associated PI3K activity, a tendency for decreased insulin-stimulated IRS-2-associated PI3K activity, and higher GLUT1 expression, being positively correlated with increased basal glucose uptake in PCOS SM [29]. The apparently normal insulin response of PCOS SM in terms of glucose uptake is possibly attributed to the increased IRS-1 and GLUT1 expression. Furthermore, the fact that IMGU is maintained in vitro but significantly impaired in vivo indicates that IR is not an intrinsic feature in PCOS SM but is greatly influenced by adverse in vivo environmental conditions.

A putative serine kinase, extrinsic to the insulin receptor, has been implicated in the abnormal pattern of phosphorylation in PCOS but has not been identified yet. Although there are at least 50 known potential serine/threonine phosphorylation sites on IRS-1, phosphorylation at both serine 312 and serine 636/639 has been frequently reported in several studies associating IRS-1 serine phosphorylation with IR [47].

The defective activation of aPKC (atypical protein kinase C), a downstream effector of PI3K, in SM of PCOS obese patients has been also involved in the pathogenesis of muscle IR in this syndrome. In humans, marked defects in aPKC activation in SM have been reported in T2DM, obesity, obesity-associated PCOS, and impaired glucose tolerance [48]. These defects in aPKC activation in SM are due to both impaired activation of IRS-1-dependent PI3K and diminished responsiveness of aPKCs to a lipid product of PI3K, called PI-3,4,5-(PO4) $)_{3}$ or PIP3. Although it is still uncertain which underlying defect comes first, the resultant defect in aPKC activation in SM contributes significantly to the development of muscle IR [48].

Despite the well established identification of several molecular abnormalities in PCOS, it remained initially unclear whether the observed defects in insulin-signaling are actually intrinsic, genetically determined to $\mathrm{SM}$, or rather acquired secondary to exposure to in vivo environmental factors such as hyperinsulinemia, hyperandrogenemia, increased circulating FFAs, or sustained hyperglycemia. According to Corbould et al. muscle IR is not an intrinsic feature in PCOS but appears rather to be significantly influenced by endogenous environmental factors [29].

Indeed, exposure to a number of molecules, including FFA, TNF- $\alpha$, glucose, amino acids, diacylglycerol (DAG), and fatty acyl-CoA, increases serine phosphorylation of IRS-1 and results in impaired insulin-signaling. These molecules 
are thought to act on IRS-1 through a variety of serine/threonine kinases including mTOR (mammalian target of rapamycin) and S6K. More specifically, FFA reduce IRS1-associated PI3K activity, impair Akt/PKB phosphorylation, and activate PKC $\theta$ (protein kinase $\mathrm{C}$ theta), a serine kinase that increases serine phosphorylation of IRS-1 [28]. Concerning diacylglycerol, a potent activator of PKC, it is thought to be an additional important lipid mediator of muscle IR [49]. High insulin levels can also stimulate IRS1 serine phosphorylation in human myoblasts, indicating that insulin can modulate its own signaling pathway [44]. Androgen excess induces muscle IR in PCOS by affecting, most possibly, postinsulin receptor signaling events. Recent in vitro data, in primary differentiated rat myotubes, have demonstrated a synergistic interaction between testosterone and insulin in phosphorylation of intracellular signaling proteins (phosphorylation of IRS-1 at serine residues) and a consequent dissociation of the insulin receptor from the PI3K signaling cascade, resulting in impaired insulin metabolic signaling [44].

(b) Human Studies. In vivo studies of PCOS patients, where serial SM biopsies were performed during hyperinsulinemiceuglycemic clamps, have revealed a significant impairment in IMGU, an increased expression of IRS-2, and normal expression of insulin receptor, IRS-1, and PI3K. These data suggest that the increased expression of IRS-2 might represent a compensatory adaptation for the decreased insulin-mediated IRS-1-associated PI3K activity, which is not, however, completely effective, since IMGU was not restored to normal [50]. Most recently, Hojlund et al. reported small reductions in insulin-stimulated phosphorylation of Akt (PKB) and AS160 (Akt substrate of $160 \mathrm{kDa}$ ) in intact muscle of women with PCOS, which was partially reversed by treatment with insulin-sensitizing agents such as pioglitazone [51].

Recently, another candidate pathogenetic mechanism for muscle IR in women with PCOS has been proposed, consisting in a defective insulin regulation of ERK 1/2 (extracellular signal-regulated kinases 1/2). Rajkhowa et al. compared the relative contribution of two distinct insulin-signaling pathways to muscle IR in nine women, diagnosed with PCOS. The study involved the Ras-ERK and the IRS-PKB pathways, mediating the mitogenic and metabolic effects of insulin, respectively, and found no significant difference in the expression, basal activity, or insulin activation of IRS-1 and PKB between PCOS subjects and controls [52]. However, there was a severe attenuation of insulin stimulation of the ERK pathway and an accompanying trend for higher basal phosphorylation of ERK 1/2 in SM biopsies obtained from nearly all women with PCOS [52]. Interestingly, the investigators observed a reduced ERK activity after acute in vivo exposure of SM to insulin, in almost all PCOS subjects of the study, contrasting with the physiologically expected increase in mitogenic ERK activity, in response to insulin stimulation. These results suggest that ERK activation might influence regulation of glucose uptake in SM and might be involved in muscle IR in women with PCOS [52].

Based on the few existing human in vivo studies, it seems that in PCOS there is a severe functional defect in the insulin-signaling cascade within SM, consisting in an abnormal phosphorylation pattern of the insulin receptor or downstream key signaling proteins.

\subsubsection{Transcriptional Defects Involved in Muscle IR in PCOS.} It has been recently demonstrated that PCOS is associated with impaired mitochondrial structural integrity and oxidative metabolism. Skov et al. studying insulin resistant women with PCOS, demonstrated a significant downregulation of the expression of nuclear-encoded genes representing mitochondrial oxidative phosphorylation, ribosomal proteins, mRNA processing reactome, translation factors, and proteasome degradation (OXPHOS), compared to control women. This effect was mainly mediated by a decrease in PGC-1a expression (PPAR- $\gamma$ coactivator-1a) and was partially restored after treatment with pioglitazone [53]. Thus, the insulin-sensitizing effects of pioglitazone may include reversal of preexisting abnormalities in ribosomal protein biosynthesis and mitochondrial biogenesis in women with PCOS [54].

Calcium transporter activity was also significantly downregulated in PCOS patients. Increasing evidence supports a modulating role for calcium influx, calmodulin and $\mathrm{Ca}^{+2} /$ calmodulin-dependent protein kinase (CaMK) in IMGU in SM [55]. An increase in cytosolic calcium and activation of CaMK induce mitochondrial biogenesis and GLUT4 expression via activation of different transcription factors, including NRF-1 and -2 (nuclear respiratory factor) and the coactivator PGC-1a [56]. Any potential dysregulation of calcium homeostasis could, therefore, have a pronounced disturbing effect on IMGU and mitochondrial functional capacity [57].

Future studies, unraveling the exact molecular mechanisms of IR in general or in SM in particular in PCOS, may help develop effective gene-based strategies in order to prevent the increased risk of early onset type 2 diabetes in women suffering from this condition.

4.2. Adrenal Disorders and Muscle IR. Adrenal disorders characterized by increased secretion of adrenocortical or adrenomedullary hormones such as hyperaldosteronism, Cushing's syndrome, hyperandrogenism, and pheochromocytoma have been associated with various metabolic disorders, including impaired glucose tolerance, IR, and overt diabetes [58]. These abnormalities constitute the end result of the adverse effects of adrenal hormones on various components of insulin action and glucose metabolism.

Adrenal hormone excess is associated with decreased insulin secretion by the pancreatic $\beta$ cell or disrupted insulin action in peripheral tissues. SM has been recently recognized as an important insulin-target site with a major role in the pathogenesis of the glucometabolic abnormalities associated with hypersecreting adrenal disorders [59].

4.2.1. Aldosterone Excess and Muscle IR. Aldosterone is the final mediator of the renin-angiotensin-aldosterone system (RAS), which mediates blood pressure control and electrolytic balance in the kidney. However, a significant body of evidence indicates that aldosterone-in concert 
with other independently acting mediators of RAS axis (renin and angiotensin)-impairs insulin secretion and metabolic signaling, resulting in impaired glucose tolerance and overt diabetes. Focusing on aldosterone, which can be significantly elevated in some patients with hypersecreting adrenal lesions, it promotes IR, inflammation, fibrosis, oxidative stress, and sodium retention, with detrimental cardiometabolic effects [60]. Recent literature data support that most of the adverse metabolic changes observed in primary hyperaldosteronism can be totally reversed after the surgical removal of the adrenal tumors or treatment with mineralocorticoid receptor blocking agents [61].

Mounting evidence supports that aldosterone exerts its diabetogenic actions by a direct effect on insulin receptor function and metabolic signaling cascade in several peripheral tissues, including cardiovascular and renal tissue, fat, liver and SM [60]. In addition, hypokalemia, as a result of aldosterone excess, can also impair both pancreatic insulin secretion and peripheral insulin action, providing an alternative explanation for the observed abnormalities in primary hyperaldosteronism [62].

However, the underlying molecular and cellular mechanisms linking aldosterone excess with changes in the glucose and insulin metabolism remain still elusive, especially regarding the contribution of SM.

In addition to its classic effects, aldosterone induces rapid (nongenomic) adverse responses in both vascular smooth muscle cells and SM. This effect is mediated by NADPH oxidase (nicotinamide adenine dinucleotide phosphate), which generates excess reactive oxygen species (ROS), redox imbalance, and oxidative stress [63]. Oxidative stress activates redox-sensitive serine kinases in these tissues, including PKC (protein kinase C), MAPKs (mitogen-activated protein kinases), c-Jun $\mathrm{NH} 2$-terminal kinase, extracellular signal-regulated kinases 1 and 2 (ERK 1/2), and p-kinase. The activation of these kinases leads to increased serine phosphorylation of IRS-1, which impairs normal binding with PI3K and results in decreased activation of PKB (Akt) and adverse downstream metabolic effects such as impaired glucose transport in many tissues, including SM [64]. This effect is further substantiated by the significant improvement in systemic insulin sensitivity, insulin-signalling, and glucose uptake by SM, after treatment with mineralocorticoid receptor blocking agents in experimental animal models of RAS hyperactivation and IR [65]. The improvement in insulin sensitivity was closely associated with decreased NADPH oxidase activity in SM, suppressed levels of ROS, and improved mitochondrial structure and function. In addition, in rat vascular smooth muscle cells, aldosterone downregulated IRS-1 expression via stimulating the production of ROS, an effect which was markedly attenuated by treatment with the selective mineralocorticoid receptor antagonist eplerenone [66].

4.2.2. Glucocorticoid Excess and Muscle IR. Chronic exposure to glucocorticoid excess, a typical feature of Cushing's syndrome, is associated with various metabolic disorders, including glucose intolerance, IR, or overt diabetes [67].
Glucocorticoids (GCs) interfere with several steps of glucose metabolism and insulin-signaling cascade, resulting in reduced IMGU and IR in most peripheral tissues, including SM. GCs may induce IR, either directly by interfering with the insulin receptor cascade in SM, or indirectly through GC-induced changes in protein and lipid metabolism [67].

Since studies into the effects of GCs on the expression of insulin receptor in SM have yielded contradictory results, the markedly reduced IMGU under conditions of GC excess has been proposed as a postreceptor defect. In vitro studies using isolated SM cells treated with dexamethasone showed a decreased expression and phosphorylation of IRS-1, PI3K, and $\mathrm{PKB} / \mathrm{Akt}$ as well as reduced GLUT4 migration to the cell surface $[68,69]$. In addition to reducing glucose uptake, GCs have also been shown to decrease glycogen synthesis rate in Wistar rats by reducing $\mathrm{PKB} / \mathrm{Akt}$ and GSK-3 (glycogen synthase kinase-3) phosphorylation [70]. Beyond experimental results, there are limited available data concerning the exact molecular effects of GCs on insulinsignaling in humans. As early as in 1988, Rebuffé-Scrive, was the first investigator who studied in detail the morphology and metabolism of SM in female patients with Cushing's syndrome [71]. In his study, leg muscle tissue of women with Cushing's syndrome was found to contain a relatively low proportion of type I fibers (insulin sensitive) and a high proportion of type IIb fibers (insulin resistant), a similar pattern of muscle fiber composition to that observed in android obesity. He also found a significantly low glycogen synthase activity in the lateral vastus muscle of the same women. This is the first study suggesting an abnormal muscle fiber composition (relative shift from type I to type IIb fibers) in a common clinical condition of chronic endogenous corticosteroid excess. In addition, healthy volunteers treated with dexamethasone for 5 days and patients exposed to longterm high-dose GCs after renal transplantation, displayed reduced glycogen synthesis rates with concomitant decreased concentration and activity of glycogen synthase in SM biopsies [72].

Some data support an indirect effect of GS on SM insulin-signaling, which is mediated through enhanced proteolysis, and thus increased circulating amino acid levels. Elevated circulating amino acids seem to inhibit insulinstimulated IRS tyrosine phosphorylation and activation of PI3K in vitro [73]. In addition, they reduce IMGU and glycogen synthesis in humans [74].

Another indirect negative effect of GCs on SM insulin sensitivity appears to be mediated through the GC-induced dyslipidemia. GCs promote whole body lipolysis, resulting in increased plasma levels of FFAs, which enhance in turn the accumulation of intramyocellular lipids (IMCLs), such as fatty acyl CoA, diacylglycerol, and ceramide, affecting negatively glucose uptake and disposal [75]. It was originally proposed by Randle in 1963 that intracellular lipids decrease insulin-mediated glucose uptake by competing with glucose for oxidation [76]. However, more recent studies have demonstrated that IMCLs reduce IMGU by interfering directly with insulin-signaling. Intracellular lipids may activate various serine kinases, such as c-Jun aminoterminal 
kinase (JNK) and IKB kinase- $\beta$ (IKK- $\beta$ ), which phosphorylate serine sites on IRS-1, resulting in suppressed insulinsignaling [75].

In summary, GCs reduce insulin sensitivity and consequently IMGU in SM, not only by directly perturbing insulin-signaling and glycogen synthesis, but also secondarily to unfavorable changes in protein and lipid metabolism, which further affect negatively the insulin-signaling cascade, in peripheral tissues, including SM.

4.2.3. Adrenal Androgens and Muscle IR. The exact relationship between increased adrenal androgens and IR remains to be elucidated. It has been shown that experimentally induced hyperinsulinemia elicited an acute decline in dehydroepiandrosterone (DHEA) and dehydroepiandrosterone sulfate (DHEA-S). However, the regulatory role of insulin on adrenal androgen production and metabolism in normal physiology or disease remains still speculative [58]. In several animal models, DHEA appears to exert potent antiobesity and antidiabetogenic actions, but such effects have not been persuasively demonstrated in humans [58]. Human studies on DHEA are limited, and more research needs to be conducted in order to determine whether the experimental observations made in animal models can be also extrapolated to man. Recent experimental evidence indicates that DHEA may act at multiple steps in the regulation of glucose metabolism in the liver, suppressing the activity of hepatic gluconeogenic enzymes [77]. However, there are no data concerning the relationship of increased adrenal androgen production and peripheral insulin action, especially at the level of SM.

4.2.4. Catecholamine Excess and Muscle IR. Pheochromocytoma, typically characterized by endogenous catecholamine excess, is associated with several glucometabolic abnormalities, ranging from impaired glucose tolerance $(25 \%-$ $75 \%)$ to overt diabetes [78]. The main underlying pathogenetic mechanism for pheochromocytoma-associated glucose dysmetabolism is the catecholamine-induced decreased insulin secretion through $\mathrm{a}_{2}$ adrenoreceptors, while the effects of catecholamines on peripheral glucose uptake seem to be less important [79]. However, in animal studies, epinephrine has been shown to induce IR in rat muscle [80]. Furthermore, Raz et al. [81] studied the effect of epinephrine in eight healthy patients and detected an inhibition of insulin-mediated glycogenesis because of an inactivation of glycogen synthase, suggesting that epinephrine inhibits insulin-mediated glucose utilization at the major site of IR namely, skeletal muscle. An additional study by Laakso et al. showed that epinephrine impairs the ability of insulin to increase SM glucose extraction in humans [82].

In summary, excessive catecholamines in patients with pheochromocytoma can induce or aggravate IR in peripheral tissues including SM, while the surgical treatment of pheochromocytoma can reverse the hyperinsulinemia and cardiometabolic abnormalities observed in these patients [79].
4.2.5. Adrenal Incidentalomas and IR. Adrenal incidentalomas (AIs) are defined as randomly discovered adrenal masses, which are diagnosed by abdominal ultrasound or computed tomography scan, performed for unrelated causes. Recent literature suggests that $10 \%-20 \%$ of solid AIs demonstrate a subclinical hormonal dysfunction, which may place patients at a higher risk for metabolic derangements such as IR [83]. Subclinical hypercortisolism is the most common abnormality detected in patients with AIs, with an average incidence of 9\% [84]. Patients with AIs have a higher prevalence of diabetes or glucose intolerance $(20 \%-$ $75 \%)$, compared with the general population [85]. AIs are considered to be both a cause and an effect of hyperinsulinemia. The alternative hypothesis that AIs are actually caused by hyperinsulinemia has been formulated by Reincke et al. [86], who studied 13 patients with AIs and found that they were all insulin resistant. He also observed a proliferative effect of insulin on adrenal cell lines in vitro, indicating that insulin can stimulate adrenocortical tumor formation. The proposed theory was that AIs can be perceived as the clinical result of sustained hyperinsulinemia, just as PCOS is regarded as the result of insulin-mediated stimulation of ovary growth [86].

In a study from Japan, all 12 patients with AIs exhibited IR, based on the steady state of plasma glucose [87]. After surgical removal of the tumors, steady state of plasma glucose was significantly decreased, compared to pre-adrenalectomy values. A further study by Ivovic et al. assessed insulin sensitivity in 22 patients with AIs and concluded that patients with AIs manifested lower insulin sensitivity than healthy controls [88].

Trying to provide an explanation for the increased risk of developing IR in patients with nonfunctioning AIs (NFAIs), Ermetici et al. have recently formulated the hypothesis of adipokine involvement [89]. Plasma IL-6, adiponectin, resistin, TNF-a, and monocyte chemoattractant protein 1 (MCP-1) levels were all found to be significantly higher in patients with NFAIs compared to controls. The pathogenetic role of proinflammatory cytokines in patients with AIs merits definitely further investigation.

In a recent study by our research team [90], in 29 patients with NFAIs, we demonstrated significant hepatic and peripheral IR, documented by both higher fasting glucose and insulin levels and abnormal glucose tolerance data, as well as an increased prevalence of several components of metabolic syndrome, such as hypertension, dyslipidemia, fatty liver disease, and central obesity. It is, therefore, useful to evaluate routinely IR in patients with AIs, since results can be quite helpful in clinical decision making [87].

4.3. Thyroid Disorders and Muscle IR. Thyroid hormones (THs) constitute important mediators of body metabolism and affect various metabolic aspects involving glucose and insulin metabolism, through a variety of mechanisms. Data from animal studies have shown that THs play a key role in the regulation and activation of insulin receptor and glucose transporter proteins, in signaling pathways and in the expression of different isoforms of SM myosin heavy chains [91]. In addition, THs regulate the differentiation, 
growth, and metabolism of virtually every cell in the human body. In SM, triiodothyronine (T3) regulates muscle fiber type and mitochondrial content through a genomic action, consisting in a direct modulation of gene transcription by ligand-dependent activation of $\mathrm{TH}$ receptors (TRs) and specific $\mathrm{TH}$ response elements (TREs). Other $\mathrm{TH}$ effects, such as modulation of ion channel activity, intracellular $\mathrm{Ca}^{2+}$ mobilization, phospholipase, and kinase activation, have been attributed to nongenomic actions of TH. This mode of action explained the $\mathrm{TH}$-induced activation of a signaling cascade involving phospholipase $\mathrm{C}$ activation, inositol triphosphate (IP3) accumulation, intracellular $\mathrm{Ca}^{2+}$ mobilization and phosphorylation of PKC and ERK 1/2, resulting ultimately in activation of plasma membrane $\mathrm{Na}^{+} / \mathrm{H}^{+}$exchangers and increased intracellular $\mathrm{pH}$ in rat SM cells [92]. Furthermore, with the same mode of action, $\mathrm{T}_{3}$ induces a rapid phosphorylation of both p38 and AMPK (AMP-dependent kinase) in SM fibers and stimulates mitochondrial biogenesis [93].

4.3.1. Hypothyroidism and Muscle IR. Hypothyroidism (HP) has been associated with disorders of glucose and insulin metabolism, involving defective insulin secretion in response to glucose, hyperinsulinemia, altered peripheral glucose disposal, and IR.

According to in vivo data, HP is associated with a decreased glucose-induced insulin secretion by the $\beta$ cells due to changes in the physicochemical properties of the islet membranes and decreased amount of islets [94].

In addition, it is suggested that $\mathrm{HP}$ is an insulin resistant state. Interestingly, even subtle decreases in the levels of $\mathrm{TH}$ within the normal range have been shown to correlate inversely with markers of IR [95]. In vivo data, emerging from studies in propylthiouracil-induced hypothyroid animals during euglycemic-hyperinsulinemic clamps, showed an association of HP with an adipokine-mediated IR [96]. Mitrou et al. showed that euglycemic patients with clinical and subclinical HP were insulin resistant. In a recent study, the same authors supported the important role of adipokines in IR, showing a meal-induced IL-6 increase, primarily involved in the observed IR, and a concomitant increase of TNF- $\alpha$, which seems to be the result rather the cause in this process [4].

The mechanisms linking HP with IR in general and in SM in particular are still under investigation. IR in HP is associated with a negative regulation of one or more intracellular enzymes involved in glucose catabolism [97]. An impaired translocation of GLUT4 transporters on the plasma membrane has been also observed in the monocytes of subjects with clinical and subclinical HP, in relation to a decreased IMGU [98]. Dimitriadis et al. documented a decreased glycogen synthesis rate at supraphysiological insulin concentrations in SM of hypothyroid rats, as well as a decreased rate of glucose oxidation at all insulin concentrations $[99,100]$. An effect of TH on insulin receptors has been suggested, but the existing data are rather conflicting, supporting either no relationship between thyroid status and the affinity of insulin receptors or diminished high affinity insulin receptors (HAIRs) in HP [101]. The effect of $\mathrm{TH}$ on insulin action in peripheral tissues such as SM has not been studied systematically in vivo. Dimitriadis et al. demonstrated a meal-induced increase in plasma insulin levels in subjects with HP and an unchanged rate of glucose uptake in the forearm muscles and AT, indicating that IR is possibly the result of diminished blood flow in AT and SM [96]. In support of this, Rochon et al. showed decreased forearm and AT blood flow and glucose disposal rates in patients with HP, during euglycemic-hyperinsulinemic clamps [102].

It is obvious that, although HP constitutes an insulin resistant state, more studies need to be done in order to clarify the underlying pathogenetic mechanisms. However, it has to be mentioned that IR appears to be similar in patients with overt clinical and subclinical HP [103, 104], while treatment with thyroxine does not restore IMGU in the forearm of patients with HP, suggesting that TH per se may not be entirely responsible for this manifestation, which seems to be a more complex interaction between tissues and molecules.

4.3.2. Hyperthyroidism and Muscle IR. Hyperthyroidism (HPR) is also associated with metabolic abnormalities, including disorders of the glucose and insulin metabolism [105].

Insulin secretory capacity seems to be disrupted in HPR, but the existing data are rather heterogeneous, suggesting increased, normal, or decreased insulin secretion. This estimation has been based on the measurement of circulating $\mathrm{C}$-peptide levels. However, when individually derived Cpeptide kinetic parameters were measured, the insulin secretory rate was significantly increased, possibly reflecting an increased response of $\beta$ cell to glucose, under increased $\mathrm{TH}$ levels. The limitation of these studies is the use of C-peptide as a marker of insulin secretion, which is biased, given its rapid clearance from the circulation in HPR [106]. However, an increase in the $\beta$-cell mass in HPR has been also reported [107]. In addition, Liggett et al. [108] showed an increased insulin secretory response to epinephrine (increased plasma C-peptide) after T3 administration, indicating an increased insulin secretory rate in HPR [108].

HPR has been also associated with hyperinsulinemia, which is considered to be compensatory for the increased insulin clearance $[103,104]$. Insulin action and IMGU in HPR are ill defined, either in general, or in SM in particular. In vitro and in vivo studies of IMGU using euglycemic hyperinsulinemic clamps showed either normal or increased IMGU [109-111]. However, IR has been documented in HPR, especially in the liver, since there is still uncertainty concerning the involvement of other peripheral tissues, including SM. Dimitriadis et al. documented IR at the fasting state in AT in HPR, which was suppressed postprandially, stimulating the glucose uptake in SM [112]. The same authors documented a postmeal induced hyperinsulinemia in subjects with HPR, as well as IR at the level of SM [113].

However, there are only few data regarding the underlying pathogenetic mechanisms of IR in HPR. The existing data regarding the number of high and low affinity insulin receptors are conflicting, suggesting either an increased or 
unaltered expression in HPR [114]. A decreased insulin stimulated glycogen synthesis has been also reported in SM from hyperthyroid subjects, indicating IR at the level of SM $[103,104]$. Dimitriadis et al. documented a markedly decreased rate of IMGU in SM, which was compensated by an increase in blood flow, due to changes either in cardiac or in vascular function [113]. The same authors have demonstrated an IGF-1-induced increase in GLUT3 and GLUT4 translocation on the monocyte surface in HPR subjects [99].

A decreased insulin-mediated stimulation of major intracellular pathways of glucose metabolism has been also reported $[99,103,109]$. HPR has been associated with an increased activity and density of $\beta$-adrenergic receptor in SM $[108,115]$, as well as a decreased muscle oxidative capacity [116].

HPR is generally thought to be an insulin-resistant state, but further studies are definitely needed in order to prove this association and reveal the underlying pathogenetic mechanisms. It has been generally suggested that THs are not the only factors involved in the initiation of the IR cascade, but they most commonly interact with various tissues and molecules, in order to regulate glucose metabolism and insulin action.

\section{Summary and Conclusions}

SM constitutes an insulin-responsive peripheral tissue with a major role in maintaining systemic glucose metabolism. In a general overview of insulin-resistant states, including PCOS as well as adrenal and thyroid disorders, IR in SM appears to be a clinically important manifestation. Specific alterations at the insulin receptor level or the signal transduction pathway have been suggested as the main underlying pathogenetic mechanisms which lead to impaired IMGU and defective glycogen synthesis.

In PCOS, muscle IR has been associated with abnormal phosphorylation of insulin-signaling proteins, altered muscle fiber composition, reduced transcapillary insulin delivery, decreased glycogen synthesis, and impaired mitochondrial oxidative metabolism.

The metabolic abnormalities associated with hypersecreting adrenal disorders constitute the end result of the adverse effects of adrenal hormones on various components of insulin action and glucose metabolism. Aldosterone is associated with IR in SM either directly through its effects on the insulin receptor function and metabolic signaling cascade, or indirectly through oxidative stress induction. GCs reduce IMGU in SM, either directly by perturbing insulinsignaling and glycogen synthesis, or indirectly through unfavorable changes in protein and lipid metabolism. Catecholamine excess can induce or aggravate IR in SM. Furthermore, AIs-including NFAIs_-are characterized by an increased prevalence of generalized and muscle IR, possibly due to the subclinical proinflammatory milieu and the biochemically silent endocrine abnormalities.

Thyroid disorders, including both hypo- and hyperthyroidism, have been associated with IR in SM and altered peripheral glucose disposal, due to impaired GLUT4 translocation, decreased glycogen synthesis, downregulated intracellular glucose catabolism, altered blood flow, and decreased muscle oxidative capacity.

Based on the data presented herein, it is strongly emphasized that all patients with common endocrine disorders such as PCOS as well as adrenal and thyroid disorders, should undergo a thorough metabolic evaluation, since IRparticularly at the level of SM-appears to be a prominent feature in these states. Far more clinical and experimental studies are required in order to fully clarify the underlying pathophysiology of the clinically meaningful relationship between endocrine disease and impaired SM insulin sensitivity.

\section{List of Important Abbreviations}

PCOS: Polycystic Ovary Syndrome

IR: Insulin Resistance

HP: $\quad$ Hypothyroidism

HPR: Hyperthyroidism

AIs: $\quad$ Adrenal Incidentalomas

NFAIs: Nonfunctioning Adrenal Incidentalomas

SM: $\quad$ Skeletal Muscle

AT: $\quad$ Adipose Tissue

IMGU: Insulin-mediated glucose uptake

GLUT4: Glucose Transporter 4

IRS-1: Insulin receptor substrate-1

PI3K: $\quad$ Phosphatidylinositol 3-kinase

Akt/PKB: Akt/Protein kinase B

aPKC: Atypical protein kinase $\mathrm{C}$

GSK-3: Glycogen synthase kinase-3

ERK 1/2: Extracellular signal-regulated kinases 1/2

AS160: Akt substrate of $160 \mathrm{kDa}$

mTOR: mammalian Target Of Rapamycin

MAPKs: Mitogen-activated Protein Kinases

IP3: Inositol Triphosphate

AMPK: AMP-dependent kinase

PKA: $\quad$ Protein kinase A

HSL: Hormone-Sensitive Lipase

TNF-a: Tumor necrosis factor-a

FFA: $\quad$ Free Fatty Acid

Il-6: Interleukin-6

$\mathrm{NF} \kappa \mathrm{B}$ : $\quad$ Nuclear Factor $\kappa \mathrm{B}$

PPAR- $\gamma$ : Peroxisome-Proliferator Activated Receptor- $\gamma$

PGC-1a: PPAR- $\gamma$ coactivator 1a

eNOS: Endothelial Nitric Oxide Synthase

NADPH: Nicotinamide Adenine Dinucleotide Phosphate

ROS: $\quad$ Reactive Oxygen Species

RAS: $\quad$ Renin-angiotensin-aldosterone system

OXPHOS: Oxidative Phosphorylation

GCs: $\quad$ Glucocorticoids

GRs: Glucocorticoid Receptors

THs: $\quad$ Thyroid Hormones

TRs: $\quad$ Thyroid hormone Receptors

TREs: Thyroid hormone response elements

DHEA: Dehydroepiandrosterone

IMCLs: Intramyocellular Lipids

HAIRs: High-Affinity Insulin Receptors. 


\section{References}

[1] D. B. Savage, K. F. Petersen, and G. I. Shulman, "Mechanisms of insulin resistance in humans and possible links with inflammation," Hypertension, vol. 45, no. 5, pp. 828-833, 2005.

[2] A. Dunaif, "Insulin resistance and the polycystic ovary syndrome: mechanism and implications for pathogenesis," Endocrine Reviews, vol. 18, no. 6, pp. 774-800, 1997.

[3] E. Maratou, D. J. Hadjidakis, A. Kollias, et al., "Studies of insulin resistance in patients with clinical and subclinical hypothyroidism," European Journal of Endocrinology, vol. 160, no. 5, pp. 785-790, 2009.

[4] P. Mitrou, E. Boutati, V. Lambadiari, et al., "Insulin resistance in hyperthyroidism: the role of IL-6 and TNF $\alpha$," European Journal of Endocrinology, vol. 162, p. 121, 2010.

[5] C. Catena, R. Lapenna, S. Baroselli, et al., "Insulin sensitivity in patients with primary aldosteronism: a follow-up study," Journal of Clinical Endocrinology and Metabolism, vol. 91, no. 9, pp. 3457-3463, 2006.

[6] E. D. Abel, O. Peroni, J. K. Kim, et al., "Adipose-selective targeting of the GLUT4 gene impairs insulin action in muscle and liver," Nature, vol. 409, no. 6821, pp. 729-733, 2001.

[7] R. A. DeFronzo, E. Jacot, E. Jequier, E. Maeder, J. Wahren, and J. P. Felber, "The effect of insulin on the disposal of intravenous glucose. Results from indirect calorimetry and hepatic and femoral venous catheterization," Diabetes, vol. 30, no. 12, pp. 1000-1007, 1981.

[8] E. Carvalho, K. Kotani, O. D. Peroni, and B. B. Kahn, "Adipose-specific overexpression of GLUT4 reverses insulin resistance and diabetes in mice lacking GLUT4 selectively in muscle," American Journal of Physiology, vol. 289, no. 4, pp. E551-E561, 2005.

[9] A. R. Saltiel and C. R. Kahn, "Insulin signalling and the regulation of glucose and lipid metabolism," Nature, vol. 414, no. 6865, pp. 799-806, 2001.

[10] L. Pirola, A. M. Johnston, and E. Van Obberghen, "Modulation of insulin action," Diabetologia, vol. 47 , no. 2, pp. 170 $184,2004$.

[11] J. R. Zierath, A. Krook, and H. Wallberg-Henriksson, "Insulin action and insulin resistance in human skeletal muscle," Diabetologia, vol. 43, no. 7, pp. 821-835, 2000.

[12] H. Ruan, N. Hacohen, T. R. Golub, L. Van Parijs, and H. F. Lodish, "Tumor necrosis factor- $\alpha$ suppresses adipocytespecific genes and activates expression of preadipocyte genes in 3T3-L1 adipocytes: nuclear factor- $\kappa \mathrm{B}$ activation by TNF- $\alpha$ is obligatory," Diabetes, vol. 51, no. 5, pp. 1319-1336, 2002.

[13] H. Ruan, P. D. G. Miles, C. M. Ladd, et al., "Profiling gene transcription in vivo reveals adipose tissue as an immediate target of tumor necrosis factor- $\alpha$ : implications for insulin resistance," Diabetes, vol. 51, no. 11, pp. 3176-3188, 2002.

[14] R. A. DeFronzo, R. Gunnarsson, O. Bjorkman, M. Olsson, and J. Wahren, "Effects of insulin on peripheral and splanchnic glucose metabolism in noninsulin-dependent (type II) diabetes mellitus," Journal of Clinical Investigation, vol. 76, no. 1, pp. 149-155, 1985.

[15] W.-S. Yang, W.-J. Lee, T. Funahashi, et al., "Weight reduction increases plasma levels of an adipose-derived antiinflammatory protein, adiponectin," Journal of Clinical Endocrinology and Metabolism, vol. 86, no. 8, pp. 3815-3819, 2001.

[16] J. Tank, J. Jordan, A. Diedrich, et al., "Bound leptin and sympathetic outflow in nonobese men," Journal of Clinical Endocrinology and Metabolism, vol. 88, no. 10, pp. 49554959, 2003.
[17] D. Freymond, C. Bogardus, M. Okubo, K. Stone, and D. Mott, "Impaired insulin-stimulated muscle glycogen synthase activation in vivo in man is related to low fasting glycogen synthase phosphatase activity," Journal of Clinical Investigation, vol. 82, no. 5, pp. 1503-1509, 1988.

[18] R. M. Reynolds, K. E. Chapman, J. R. Seckl, B. R. Walker, P. M. McKeigue, and H. O. Lithell, "Skeletal muscle glucocorticoid receptor density and insulin resistance," Journal of the American Medical Association, vol. 287, no. 19, pp. 25052506, 2002.

[19] E. J. Barrett, E. M. Eggleston, A. C. Inyard, et al., "The vascular actions of insulin control its delivery to muscle and regulate the rate-limiting step in skeletal muscle insulin action," Diabetologia, vol. 52, no. 5, pp. 752-764, 2009.

[20] A. D. Baron, "Hemodynamic actions of insulin," American Journal of Physiology, vol. 267, no. 2, pp. E187-E202, 1994.

[21] A. D. Baron, M. Laakso, G. Brechtel, and S. V. Edelman, "Mechanism of insulin resistance in insulin-dependent diabetes mellitus: a major role for reduced skeletal muscle blood flow," Journal of Clinical Endocrinology and Metabolism, vol. 73, no. 3, pp. 637-643, 1991.

[22] M. Raitakari, P. Nuutila, J. Knuuti, et al., "Effects of insulin on blood flow and volume in skeletal muscle of patients with IDDM: studies using [15O]H2O, [15O]CO, and positron emission tomography," Diabetes, vol. 46, no. 12, pp. 20172021, 1997.

[23] A. D. Baron, G. Brechtel-Hook, A. Johnson, J. Cronin, R. Leaming, and H. O. Steinberg, "Effect of perfusion rate on the time course of insulin-mediated skeletal muscle glucose uptake," American Journal of Physiology, vol. 271, no. 6, pp. E1067-E1072, 1996.

[24] H. Wang, A. X. Wang, Z. Liu, and E. J. Barrett, "Insulin signaling stimulates insulin transport by bovine aortic endothelial cells," Diabetes, vol. 57, no. 3, pp. 540-547, 2008.

[25] E. H. Serné, R. G. Ijzerman, R. O. B. Gans, et al., "Direct evidence for insulin-induced capillary recruitment in skin of healthy subjects during physiological hyperinsulinemia," Diabetes, vol. 51, no. 5, pp. 1515-1522, 2002.

[26] D. A. Ehrmann, "Polycystic ovary syndrome," New England Journal of Medicine, vol. 352, no. 12, pp. 1223-1236, 2005.

[27] R. S. Legro, A. R. Kunselman, W. C. Dodson, and A. Dunaif, "Prevalence and predictors of risk for type 2 diabetes mellitus and impaired glucose tolerance in polycystic ovary syndrome: a prospective, controlled study in 254 affected women," Journal of Clinical Endocrinology and Metabolism, vol. 84, no. 1, pp. 165-169, 1999.

[28] A. M. Venkatesan, A. Dunaif, and A. Corbould, "Insulin resistance in polycystic ovary syndrome: progress and paradoxes," Recent Progress in Hormone Research, vol. 56, pp. 295$308,2001$.

[29] A. Corbould, Y.-B. Kim, J. F. Youngren, et al., "Insulin resistance in the skeletal muscle of women with PCOS involves intrinsic and acquired defects in insulin signaling," American Journal of Physiology, vol. 288, no. 5, pp. E1047E1054, 2005.

[30] T. P. Ciaraldi, A. El-Roeiy, Z. Madar, D. Reichart, J. M. Olefsky, and S. S. C. Yen, "Cellular mechanisms of insulin resistance in polycystic ovarian syndrome," Journal of Clinical Endocrinology and Metabolism, vol. 75, no. 2, pp. 577-583, 1992.

[31] A. Corbould, "Effects of androgens on insulin action in women: is androgen excess a component of female metabolic syndrome?" Diabetes/Metabolism Research and Reviews, vol. 24, no. 7, pp. 520-532, 2008. 
[32] F. Gonzalez, K. Thusu, E. Abdel-Rahman, A. Prabhala, M. Tomani, and P. Dandona, "Elevated serum levels of tumor necrosis factor alpha in normal-weight women with polycystic ovary syndrome," Metabolism, vol. 48, no. 4, pp. 437-441, 1999.

[33] I. Tarkun, B. Çetinarslan, E. Türemen, Z. Cantürk, and M. Biyikli, "Association between circulating tumor necrosis factor-alpha, interleukin-6, and insulin resistance in normalweight women with polycystic ovary syndrome," Metabolic Syndrome and Related Disorders, vol. 4, no. 2, pp. 122-128, 2006.

[34] B. Pehlivanov and M. Mitkov, "Serum leptin levels correlate with clinical and biochemical indices of insulin resistance in women with polycystic ovary syndrome," European Journal of Contraception and Reproductive Health Care, vol. 14, no. 2, pp. 153-159, 2009.

[35] M. Yilmaz, N. Bukan, H. Demirc, et al., "Serum resistin and adiponectin levels in women with polycystic ovary syndrome," Gynecological Endocrinology, vol. 25, no. 4, pp. 246-252, 2009.

[36] A. Senay, B. Mithat, T. Alpaslan, K. Ebru, and G. Deniz, "Serum resistin and adiponectin levels in women with polycystic ovary syndrome," Gynecological Endocrinology, vol. 26, no. 3, pp. 161-166, 2010.

[37] I. Ek, P. Arner, M. Rydén, et al., "A unique defect in the regulation of visceral fat cell lipolysis in the polycystic ovary syndrome as an early link to insulin resistance," Diabetes, vol. 51, no. 2, pp. 484-492, 2002.

[38] J. E. Nestler, D. J. Jakubowicz, A. F. de Vargas, C. Brik, N. Quintero, and F. Medina, "Insulin stimulates testosterone biosynthesis by human thecal cells from women with polycystic ovary syndrome by activating its own receptor and using inositolglycan mediators as the signal transduction system," Journal of Clinical Endocrinology and Metabolism, vol. 83, no. 6, pp. 2001-2005, 1998.

[39] J. E. Nestler, L. P. Powers, D. W. Matt, et al., "A direct effect of hyperinsulinemia on serum sex hormone-binding globulin levels in obese women with the polycystic ovary syndrome," Journal of Clinical Endocrinology and Metabolism, vol. 72, no. 1, pp. 83-89, 1991.

[40] E. Diamanti-Kandarakis, G. Argyrakopoulou, F. Economou, E. Kandaraki, and M. Koutsilieris, "Defects in insulin signaling pathways in ovarian steroidogenesis and other tissues in polycystic ovary syndrome (PCOS)," Journal of Steroid Biochemistry and Molecular Biology, vol. 109, no. 3-5, pp. 242-246, 2008.

[41] A. Corbould, H. Zhao, S. Mirzoeva, F. Aird, and A. Dunaif, "Enhanced mitogenic signaling in skeletal muscle of women with polycystic ovary syndrome," Diabetes, vol. 55, no. 3, pp. 751-759, 2006.

[42] A. Holmang, J. Svedberg, E. Jennische, and P. Bjorntorp, "Effects of testosterone on muscle insulin sensitivity and morphology in female rats," American Journal of Physiology, vol. 259, no. 4, pp. E555-E560, 1990.

[43] A. Holmäng, M. Niklasson, B. Rippe, and P. Lönnroth, "Insulin insensitivity and delayed transcapillary delivery of insulin in oophorectomized rats treated with testosterone," Acta Physiologica Scandinavica, vol. 171, no. 4, pp. 427-438, 2001.

[44] M. C. Allemand, B. A. Irving, Y. W. Asmann, et al., "Effect of testosterone on insulin stimulated IRS1 Ser phosphorylation in primary rat myotubes-a potential model for PCOSrelated insulin resistance," PLOS ONE, vol. 4, no. 1, article e4274, 2009.
[45] F. Giallauria, S. Palomba, C. Vigorito, et al., "Androgens in polycystic ovary syndrome: the role of exercise and diet," Seminars in Reproductive Medicine, vol. 27, no. 4, pp. 306315, 2009.

[46] A. Dunaif, J. Xia, C.-B. Book, E. Schenker, and Z. Tang, "Excessive insulin receptor serine phosphorylation in cultured fibroblasts and in skeletal muscle. A potential mechanism for insulin resistance in the polycystic ovary syndrome," Journal of Clinical Investigation, vol. 96, no. 2, pp. 801-810, 1995.

[47] K. Bouzakri, M. Roques, P. Gual, et al., "Reduced activation of phosphatidylinositol-3 kinase and increased serine 636 phosphorylation of insulin receptor substrate-1 in primary culture of skeletal muscle cells from patients with type 2 diabetes," Diabetes, vol. 52, no. 6, pp. 1319-1325, 2003.

[48] R. V. Farese, M. P. Sajan, and M. L. Standaert, "Atypical protein kinase $\mathrm{C}$ in insulin action and insulin resistance," Biochemical Society Transactions, vol. 33, no. 2, pp. 350-353, 2005.

[49] M. Straczkowski and I. Kowalska, "The role of skeletal muscle sphingolipids in the development of insulin resistance," Review of Diabetic Studies, vol. 5, no. 1, pp. 13-24, 2008.

[50] A. Dunaif, X. Wu, A. Lee, and E. Diamanti-Kandarakis, "Defects in insulin receptor signaling in vivo in the polycystic ovary syndrome (PCOS)," American Journal of Physiology, vol. 281, no. 2, pp. E392-E399, 2001.

[51] K. Hojlund, D. Glintborg, N. R. Andersen, et al., "Impaired insulin-stimulated phosphorylation of akt and AS160 in skeletal muscle of women with polycystic ovary syndrome is reversed by pioglitazone treatment," Diabetes, vol. 57 , no. 2 , pp. 357-366, 2008.

[52] M. Rajkhowa, S. Brett, D. J. Cuthbertson, et al., "Insulin resistance in polycystic ovary syndrome is associated with defective regulation of ERK1/2 by insulin in skeletal muscle in vivo," Biochemical Journal, vol. 418, no. 3, pp. 665-671, 2009.

[53] V. Skov, D. Glintborg, S. Knudsen, et al., "Reduced expression of nuclear-encoded genes involved in mitochondrial oxidative metabolism in skeletal muscle of insulin-resistant women with polycystic ovary syndrome," Diabetes, vol. 56, no. 9, pp. 2349-2355, 2007.

[54] V. Skov, D. Glintborg, S. Knudsen, et al., "Pioglitazone enhances mitochondrial biogenesis and ribosomal protein biosynthesis in skeletal muscle in polycystic ovary syndrome," PLoS ONE, vol. 3, no. 6, article e2466, 2008.

[55] J. T. Lanner, A. Katz, P. Tavi, et al., "The role of $\mathrm{Ca}^{2+}$ influx for insulin-mediated glucose uptake in skeletal muscle," Diabetes, vol. 55, no. 7, pp. 2077-2083, 2006.

[56] E. O. Ojuka, "Role of calcium and AMP kinase in the regulation of mitochondrial biogenesis and GLUT4 levels in muscle," Proceedings of the Nutrition Society, vol. 63, no. 2, pp. 275-278, 2004.

[57] J. Levy, "Abnormal cell calcium homeostasis in type 2 diabetes mellitus: a new look on old disease," Endocrine, vol. 10, no. 1, pp. 1-6, 1999.

[58] J. E. Nestler and M. A. McClanahan, "Diabetes and adrenal disease," Bailliere's Clinical Endocrinology and Metabolism, vol. 6, no. 4, pp. 829-847, 1992.

[59] S. P. Thomson, C. S. Stump, L. R. Kurukulasuriya, and J. R. Sowers, "Adrenal steroids and the metabolic syndrome," Current Hypertension Reports, vol. 9, no. 6, pp. 512-519, 2007. 
[60] J. R. Sowers, A. Whaley-Connell, and M. Epstein, "Narrative review: the emerging clinical implications of the role of aldosterone in the metabolic syndrome and resistant hypertension," Annals of Internal Medicine, vol. 150, no. 11, pp. 776-783, 2009.

[61] G. Giacchetti, V. Ronconi, F. Turchi, et al., "Aldosterone as a key mediator of the cardiometabolic syndrome in primary aldosteronism: an observational study," Journal of Hypertension, vol. 25, no. 1, pp. 177-186, 2007.

[62] L. M. Mosso, C. A. Carvajal, A. Maiz, et al., "A possible association between primary aldosteronism and a lower $\beta$ cell function," Journal of Hypertension, vol. 25, no. 10, pp. 2125-2130, 2007.

[63] S. L. Liu, S. Schmuck, J. Z. Chorazcyzewski, R. Gros, and R. D. Feldman, "Aldosterone regulates vascular reactivity: shortterm effects mediated by phosphatidylinositol 3-kinasedependent nitric oxide synthase activation," Circulation, vol. 108, no. 19, pp. 2400-2406, 2003.

[64] G. E. Callera, R. M. Touyz, R. C. Tostes, et al., "Aldosterone activates vascular p38MAP kinase and NADPH oxidase via c-Src," Hypertension, vol. 45, no. 4, pp. 773-779, 2005.

[65] G. Lastra, A. Whaley-Connell, C. Manrique, et al., "Low-dose spironolactone reduces reactive oxygen species generation and improves insulin-stimulated glucose transport in skeletal muscle in the TG(mRen2)27 rat," American Journal of Physiology, vol. 295, no. 1, pp. E110-E116, 2008.

[66] H. Hitomi, H. Kiyomoto, A. Nishiyama, et al., "Aldosterone suppresses insulin signaling via the downregulation of insulin receptor substrate-1 in vascular smooth muscle cells," Hypertension, vol. 50, no. 4, pp. 750-755, 2007.

[67] D. H. van Raalte, D. M. Ouwens, and M. Diamant, "Novel insights into glucocorticoid-mediated diabetogenic effects: towards expansion of therapeutic options?" European Journal of Clinical Investigation, vol. 39, no. 2, pp. 81-93, 2009.

[68] M. J. A. Saad, F. Folli, J. A. Kahn, and C. R. Kahn, "Modulation of insulin receptor, insulin receptor substrate1 , and phosphatidylinositol 3-kinase in liver and muscle of dexamethasone-treated rats," Journal of Clinical Investigation, vol. 92, no. 4, pp. 2065-2072, 1993.

[69] S. P. Weinstein, C. M. Wilson, A. Pritsker, and S. W. Cushman, "Dexamethasone inhibits insulin-stimulated recruitment of GLUT4 to the cell surface in rat skeletal muscle," Metabolism, vol. 47, no. 1, pp. 3-6, 1998.

[70] J. Ruzzin, A. S. Wagman, and J. Jensen, "Glucocorticoidinduced insulin resistance in skeletal muscles: defects in insulin signalling and the effects of a selective glycogen synthase kinase-3 inhibitor," Diabetologia, vol. 48, no. 10, pp. 2119-2130, 2005.

[71] M. Rebuffé-Scrive, M. Krotkiewski, J. Elfverson, and P. Björntorp, "Muscle and adipose tissue morphology and metabolism in Cushing's syndrome," Journal of Clinical Endocrinology and Metabolism, vol. 67, no. 6, pp. 1122-1128, 1988.

[72] J. E. Henriksen, F. Alford, A. Vaag, A. Handberg, and H. BeckNielsen, "Intracellular skeletal muscle glucose metabolism is differentially altered by dexamethasone treatment of normoglycemic relatives of type 2 diabetic patients," Metabolism, vol. 48, no. 9, pp. 1128-1135, 1999.

[73] M. E. Patti, E. Brambilla, L. Luzi, E. J. Landaker, and C. R. Kahn, "Bidirectional modulation of insulin action by amino acids," Journal of Clinical Investigation, vol. 101, pp. 15191529, 1998.
[74] M. Krebs, M. Krssak, E. Bernroider, et al., "Mechanism of amino acid-induced skeletal muscle insulin resistance in humans," Diabetes, vol. 51, no. 3, pp. 599-605, 2002.

[75] G. Perseghin, K. Petersen, and G. I. Shulman, "Cellular mechanism of insulin resistance: potential links with inflammation," International Journal of Obesity, vol. 27, supplement 3, pp. S6-S11, 2003.

[76] P. J. Randle, P. B. Garland, C. N. Hales, and E. A. Newsholme, "The glucose fatty-acid cycle. Its role in insulin sensitivity and the metabolic disturbances of diabetes mellitus," The Lancet, vol. 281, no. 7285, pp. 785-789, 1963.

[77] R. Yamashita, T. Saito, S. Satoh, K. Aoki, Y. Kaburagi, and H. Sekihara, "Effects of dehydroepiandrosterone on gluconeogenic enzymes and glucose uptake in human hepatoma cell line, HepG2," Endocrine Journal, vol. 52, no. 6, pp. 727733, 2005.

[78] G. Stenström, L. Sjöström, and U. Smith, "Diabetes mellitus in phaeochromocytoma. Fasting blood glucose levels before and after surgery in 60 patients with phaeochromocytoma," Acta Endocrinologica, vol. 106, no. 4, pp. 511-515, 1984.

[79] T. D. Wiesner, M. Blüher, M. Windgassen, and R. Paschke, "Improvement of insulin sensitivity after adrenalectomy in patients with pheochromocytoma," Journal of Clinical Endocrinology and Metabolism, vol. 88, no. 8, pp. 3632-3636, 2003.

[80] M. Niklasson, A. Holmäng, and P. Lönnroth, "Induction of rat muscle insulin resistance by epinephrine is accompanied by increased interstitial glucose and lactate concentrations," Diabetologia, vol. 41, no. 12, pp. 1467-1473, 1998.

[81] I. Raz, A. Katz, and M. K. Spencer, "Epinephrine inhibits insulin-mediated glycogenesis but enhances glycolysis in human skeletal muscle," American Journal of Physiology, vol. 260, no. 3, part 1, pp. E430-E435, 1991.

[82] M. Laakso, S. V. Edelman, G. Brechtel, and A. D. Baron, "Effects of epinephrine on insulin-mediated glucose uptake in whole body and leg muscle in humans: role of blood flow," American Journal of Physiology, vol. 263, no. 2, part 1, pp. E199-E204, 1992.

[83] M. D. Stifelman and D. M. Fenig, "Work-up of the functional adrenal mass," Current Urology Reports, vol. 6, no. 1, pp. 6371, 2005.

[84] N. S. Ross and D. C. Aron, "Hormonal evaluation of the patient with an incidentally discovered adrenal mass," New England Journal of Medicine, vol. 323, no. 20, pp. 1401-1405, 1990.

[85] L. Barzon, N. Sonino, F. Fallo, G. Palu, and M. Boscaro, "Prevalence and natural history of adrenal incidentalomas," European Journal of Endocrinology, vol. 149, no. 4, pp. 273285, 2003.

[86] M. Reincke, M. Faßnacht, S. Väth, P. Mora, and B. Allolio, "Adrenal incidentalomas: a manifestation of the metabolic syndrome?” Endocrine Research, vol. 22, no. 4, pp. 757-761, 1996.

[87] S. Midorikawa, H. Sanada, S. Hashimoto, T. Suzuki, and T. Watanabe, "The improvement of insulin resistance in patients with adrenal incidentaloma by surgical resection," Clinical Endocrinology, vol. 54, no. 6, pp. 797-804, 2001.

[88] M. Ivovic, S. Vujović, Z. Penezić, M. Zarković, and M. Drezgić, "Insulin sensitivity in patients with adrenal incidentaloma," Srpski Arhiv za Celokupno Lekarstvo, vol. 134, no. 78, pp. 315-319, 2006.

[89] F. Ermetici, A. E. Malavazos, S. Corbetta, et al., "Adipokine levels and cardiovascular risk in patients with adrenal incidentaloma," Metabolism, vol. 56, no. 5, pp. 686-692, 2007. 
[90] M. Peppa, E. Boutati, C. Koliaki, et al., "Insulin resistance and metabolic syndrome in patients with nonfunctioning adrenal incidentalomas: a cause-effect relationship?" Metabolism. (2010) In press.

[91] F. Amati, J. J. Dubé, M. Stefanovic-Racic, F. G. Toledo, and B. H. Goodpaster, "Improvements in insulin sensitivity are blunted by subclinical hypothyroidism," Medicine and Science in Sports and Exercise, vol. 41, no. 2, pp. 265-269, 2009.

[92] S. D’Arezzo, S. Incerpi, F. B. Davis, et al., "Rapid nongenomic effects of 3,5,3'-triiodo-L-thyronine on the intracellular $\mathrm{pH}$ of L-6 myoblasts are mediated by intracellular calcium mobilization and kinase pathways," Endocrinology, vol. 145, no. 12, pp. 5694-5703, 2004.

[93] I. Irrcher, D. R. Walkinshaw, T. E. Sheehan, and D. A. Hood, "Thyroid hormone $\left(\mathrm{T}_{3}\right)$ rapidly activates p38 and AMPK in skeletal muscle in vivo," Journal of Applied Physiology, vol. 104, no. 1, pp. 178-185, 2008.

[94] G. B. Diaz, A. A. Paladini, M. E. Garcia, and J. J. Gagliardino, "Changes induced by hypothyroidism in insulin secretion and in the properties of islet plasma membranes," Archives Internationales de Physiologie, de Biochimie et de Biophysique, vol. 101, no. 5, pp. 263-269, 1993.

[95] A. Roos, S. J. L. Bakker, T. P. Links, R. O. B. Gans, and B. H. R. Wolffenbuttel, "Thyroid function is associated with components of the metabolic syndrome in euthyroid subjects," Journal of Clinical Endocrinology and Metabolism, vol. 92, no. 2, pp. 491-496, 2007.

[96] G. Dimitriadis, P. Mitrou, V. Lambadiari, et al., "Insulin action in adipose tissue and muscle in hypothyroidism," Journal of Clinical Endocrinology and Metabolism, vol. 91, no. 12, pp. 4930-4937, 2006.

[97] M. P. Czech, C. C. Malbon, K. Kerman, W. Gitomer, and P. F. Pilch, "Effect of thyroid status on insulin action in rat adipocytes and skeletal muscle," Journal of Clinical Investigation, vol. 66, no. 3, pp. 574-582, 1980.

[98] E. Maratou, D. J. Hadjidakis, A. Kollias, et al., "Studies of insulin resistance in patients with clinical and subclinical hypothyroidism," European Journal of Endocrinology, vol. 160, no. 5, pp. 785-790, 2009.

[99] G. D. Dimitriadis, B. Leighton, M. Parry-Billings, D. West, and E. A. Newsholme, "Effect of hypothyroidism on the sensitivity of glycolysis and glycogen synthesis to insulin in the soleus muscle of the rat," Biochemical Journal, vol. 257, no. 2, pp. 369-373, 1989.

[100] G. Dimitriadis, M. Parry-Billings, S. Bevan, et al., "The effects of insulin on transport and metabolism of glucose in skeletal muscle from hyperthyroid and hypothyroid rats," European Journal of Clinical Investigation, vol. 27, no. 6, pp. 475-483, 1997.

[101] P. Mackowiak, E. Ginalska, E. Nowak-Strojec, and T. Szkudelski, "The influence of hypo- and hyperthyreosis on insulin receptors and metabolism," Archives of Physiology and Biochemistry, vol. 107, no. 4, pp. 273-279, 1999.

[102] C. Rochon, I. Tauveron, C. Dejax, et al., "Response of glucose disposal to hyperinsulinaemia in human hypothyroidism and hyperthyroidism," Clinical Science, vol. 104, no. 1, pp. 7-15, 2003.

[103] G. Dimitriadis, B. Baker, H. Marsh, et al., "Effect of thyroid hormone excess on action, secretion, and metabolism of insulin in humans," The American Journal of Physiology, vol. 248, no. 5, pp. E593-E601, 1985.
[104] G. Dimitriadis, E. Maratou, E. Boutati, et al., "IGF-I increases the recruitment of GLUT4 and GLUT3 glucose transporters on cell surface in hyperthyroidism," European Journal of Endocrinology, vol. 158, no. 3, pp. 361-366, 2008.

[105] E. Resmini, F. Minuto, A. Colao, and D. Ferone, "Secondary diabetes associated with principal endocrinopathies: the impact of new treatment modalities," Acta Diabetologica, vol. 46, no. 2, pp. 85-95, 2009.

[106] P. E. Harris, M. Walker, F. Clark, P. D. Home, and K. G. M. M. Alberti, "Forearm muscle metabolism in primary hypothyroidism," European Journal of Clinical Investigation, vol. 23, no. 9, pp. 585-588, 1993.

[107] N. M. O’Meara, J. D. Blackman, J. Sturis, and K. S. Polonsky, "Alterations in the kinetics of C-peptide and insulin secretion in hyperthyroidism," Journal of Clinical Endocrinology and Metabolism, vol. 76, no. 1, pp. 79-84, 1993.

[108] S. B. Liggett, S. D. Shah, and P. E. Cryer, "Increased fat and skeletal muscle $\beta$-adrenergic receptors but unaltered metabolic and hemodynamic sensitivitiy to epinephrine in vivo in experimental human thyrotoxicosis," Journal of Clinical Investigation, vol. 83, no. 3, pp. 803-809, 1989.

[109] J.-P. Randin, L. Tappy, and B. Scazziga, "Insulin sensitivity and exogenous insulin clearance in Graves' disease. Measurement by the glucose clamp technique and continuous indirect calorimetry," Diabetes, vol. 35, no. 2, pp. 178-181, 1986.

[110] M. Laville, J. P. Riou, and P. F. Bougneres, "Glucose metabolism in experimental hyperthyroidism: intact in vivo sensitivity to insulin with abnormal binding and increased glucose turnover," Journal of Clinical Endocrinology and Metabolism, vol. 58, no. 6, pp. 960-965, 1984.

[111] S. P. Weinstein, E. O’Boyle, and R. S. Haber, “Thyroid hormone increases basal and insulin-stimulated glucose transport in skeletal muscle: the role of GLUT4 glucose transporter expression," Diabetes, vol. 43, no. 10, pp. 11851189, 1994.

[112] G. Dimitriadis, P. Mitrou, V. Lambadiari, et al., "Glucose and lipid fluxes in the adipose tissue after meal ingestion in hyperthyroidism," Journal of Clinical Endocrinology and Metabolism, vol. 91, no. 3, pp. 1112-1118, 2006.

[113] G. Dimitriadis, P. Mitrou, V. Lambadiari, et al., "Insulinstimulated rates of glucose uptake in muscle in hyperthyroidism: the importance of blood flow," Journal of Clinical Endocrinology and Metabolism, vol. 93, no. 6, pp. 2413-2415, 2008.

[114] J. P. Randin, B. Scazziga, E. Jequier, and J. P. Felber, "Study of glucose and lipid metabolism by continuous indirect calorimetry in Graves' disease: effect of an oral glucose load," Journal of Clinical Endocrinology and Metabolism, vol. 61, no. 6, pp. 1165-1171, 1985.

[115] W. H. Martin III, E. Korte, T. K. Tolley, and J. E. Saffitz, "Skeletal muscle $\beta$-adrenoceptor distribution and responses to isoproterenol in hyperthyroidism," American Journal of Physiology, vol. 262, no. 4, pp. E504-E510, 1992.

[116] W. H. Martin III, R. J. Spina, E. Korte, et al., "Mechanisms of impaired exercise capacity in short duration experimental hyperthyroidism," Journal of Clinical Investigation, vol. 88, no. 6, pp. 2047-2053, 1991. 

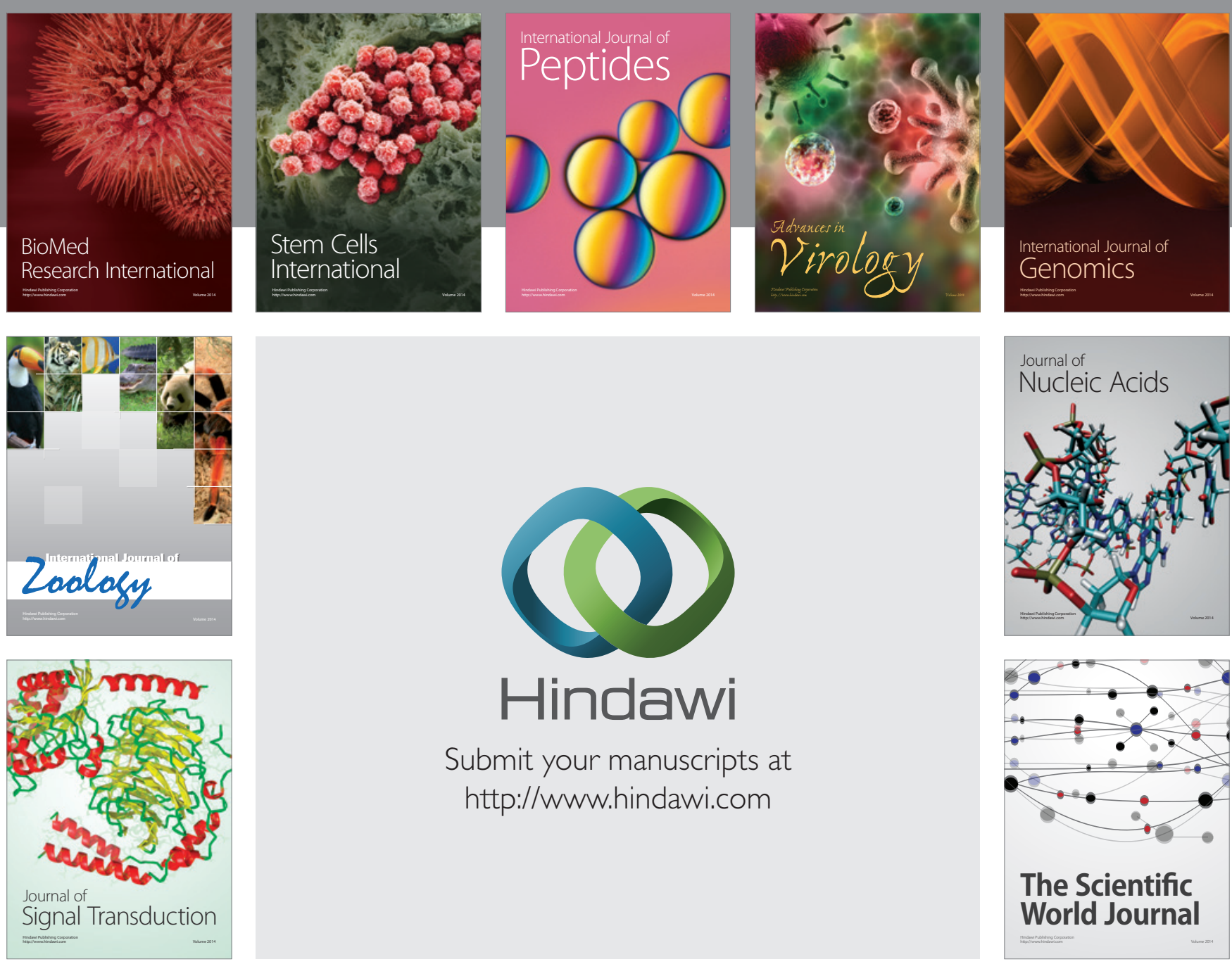

Submit your manuscripts at

http://www.hindawi.com
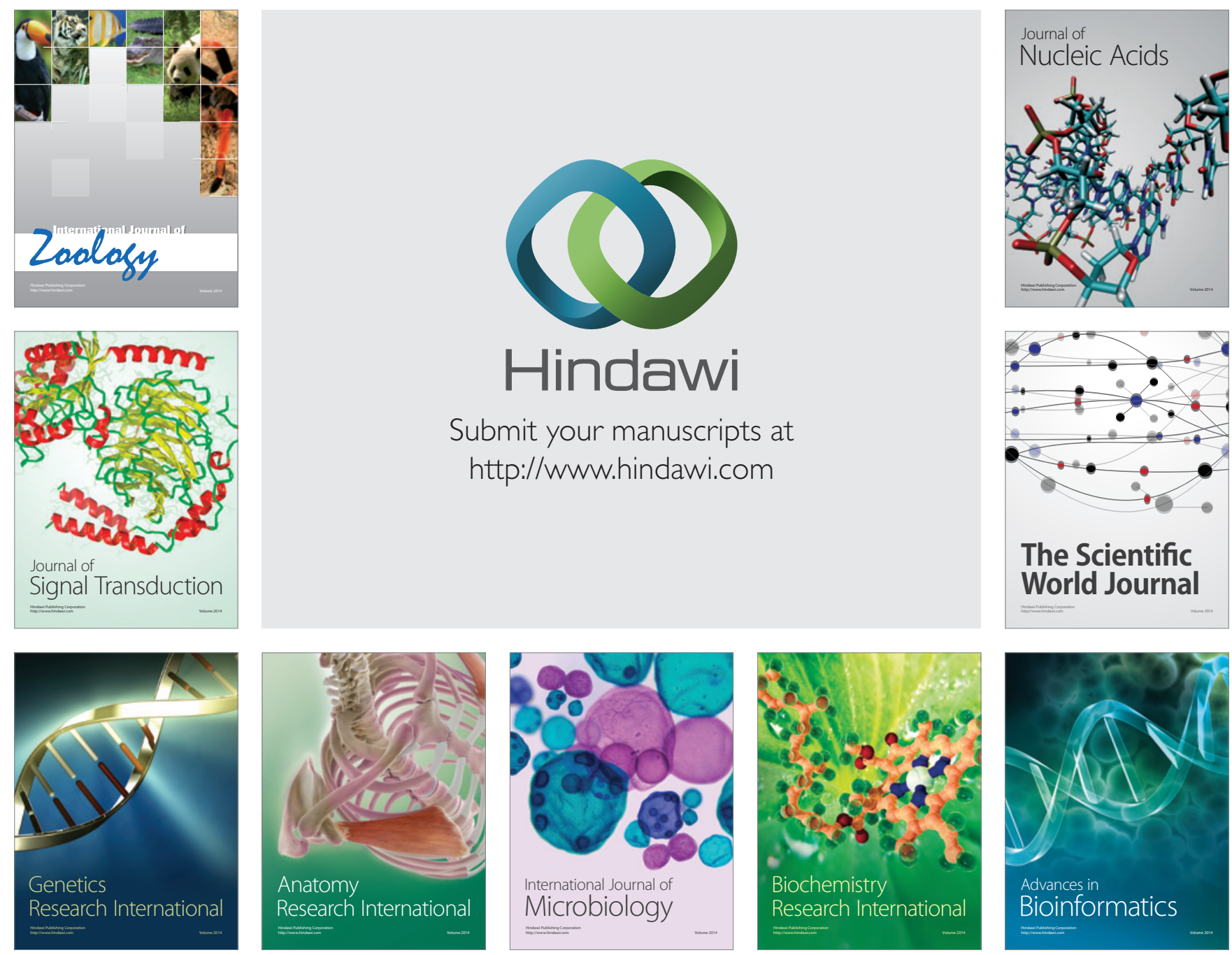

The Scientific World Journal
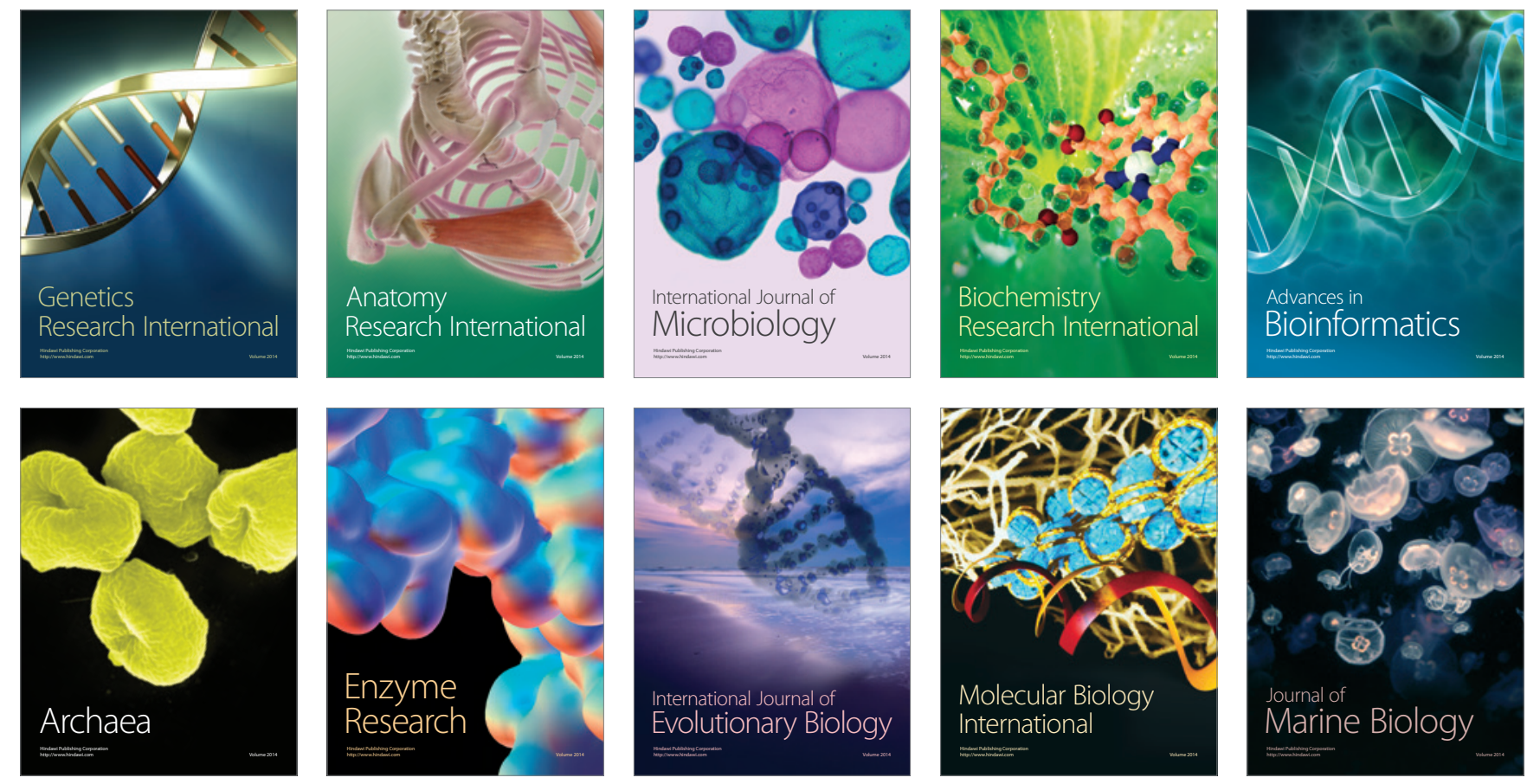